\title{
ACCEPTANCE OF AN ANALGESIC SUPPOSITORY FOR POST-OPERATIVE ANALGESIA IN CAESAREAN SECTION
}

\author{
Anju Mariam Jacobㅁ, Resmy C. R2, P. V. Ajayan ${ }^{3}$
}

${ }^{1}$ Associate Professor, Department of Anaesthesiology, Government Medical College, Thrissur.

${ }^{2}$ Associate Professor, Department of Obstetrics and Gynaecology, Government Medical College, Thrissur. ${ }_{3}^{3}$ Additional Professor, Department of Otorhinolaryngology, Government Medical College, Thrissur.

\begin{abstract}
BACKGROUND

The aim of this study is to analyse the acceptance of the rectal route of Diclofenac for postoperative analgesia in post caesarean patients as second dose analgesia after they had been given pre-emptive analgesia with rectal diclofenac. The rectal route of drug administration has many advantages over other alternate routes. Rectal route may not be accepted by most individuals in spite of its well established advantages. In this study, all patients were given prior information regarding the advantages of rectal diclofenac. There are only a few studies regarding the acceptance of the rectal route of drug administration. Awareness of the reasons for not preferring this route may help improve the acceptance of rectal drug delivery in the future.
\end{abstract}

\section{MATERIALS AND METHODS}

An analytical, questionnaire-based study was done on 100 ASA 1 and 2 patients who were undergoing elective caesarean sections under lumbar subarachnoid block. The study was conducted over a period of 6 months in a tertiary care setting. All cases were given preoperative counselling regarding the advantages of rectal diclofenac. Soon after lumbar subarachnoid block was administered in the lateral decubitus position, first dose of diclofenac was administered rectally. At the time patient complained of pain, she was asked about the requirement of further analgesia and if so the preferred route of administration. The number of patients who opted for repeat dose of rectal suppository was noted and the reason for denial of a repeat dose per rectum was recorded.

\section{RESULTS}

100 patients were given pre-emptive rectal diclofenac suppository for postoperative pain relief; 7 patients did not require second dose analgesia. Of the remaining 93 patients 21 patients opted for the rectal route, 68 patients opted for oral route and 4 patients opted for intramuscular route. Of the reasons cited for non-acceptance of second dose rectal diclofenac, the commonest cause put forward was lack of privacy.

\section{CONCLUSION}

Ensuring privacy, especially in the postoperative period, for the postpartum patient will improve the acceptance of rectal diclofenac. Patient education and information leaflets may also improve acceptance of an alternate route of drug delivery.

\section{KEYWORDS}

Analgesic, Suppository, Postoperative Analgesia, Caesarean Section.

HOW TO CITE THIS ARTICLE: Jacob AM, Resmy CR, Ajayan PV. Acceptance of an analgesic suppository for post-operative analgesia in caesarean section. J. Evolution Med. Dent. Sci. 2016;5(94):6915-6918, DOI: 10. 14260/jemds/2016/1565

\section{BACKGROUND}

Pain is one of the most feared symptoms, which a man is trying to alleviate and conquer since ages. Although effective pain control is essential for optimal care of patients, despite advances in knowledge of pathophysiology, pharmacology and development of more effective techniques for postoperative pain control, many patients continue to experience considerable discomfort postoperatively. Postoperative pain is unique by its transitory nature, which makes it more amenable to treatment.

Diclofenac, being an NSAID is thought to act by inhibiting prostaglandin synthesis. ${ }^{1}$

Financial or Other, Competing Interest: None.

Submission 16-10-2016, Peer Review 12-11-2016,

Acceptance 18-11-2016, Published 24-11-2016.

Corresponding Author:

Dr. Anju Mariam Jacob,

Associate Professor,

Department of Anaesthesiology,

Government Medical College,

Thrissur.

E-mail: anjayacs@gmail.com

DOI: $10.14260 /$ jemds/2016/1565
Hence, its efficacy in post-caesarean analgesia by the reduction of pain from uterine contractions and surgical wound pain. ${ }^{2}$ This analgesic action prevents central sensitisation. A centrally acting anti-nociceptive effect has been postulated. ${ }^{3}$ An interaction with the central opioid system has also been suggested. ${ }^{4}$ Thus, diclofenac abolishes both visceral and somatic pain.

Drug administration through the rectal route has greater bioavailability. 5 The rectal route avoids gastric irritation caused by oral drugs. 6 The present day slow release rectal suppositories help maintain blood levels for a longer time. ${ }^{7}$ The only hitch encountered in the rectal route is its acceptance. This does not pose a great problem when it is preemptively used in patients undergoing Caesarean sections, as they are subjected to bladder catheterisation preoperatively and vaginal toilet postoperatively. But acceptance levels of second dose of rectal suppository, even though has many advantages over traditional routes like oral, intravenous, intramuscular is not yet studied. This study was conducted to find out the acceptance of post-operative rectal suppository for analgesia after they have been administered pre-emptive analgesia rectally. 


\section{MATERIALS AND METHODS}

This was an analytical study conducted in 100 ASA 1 and 2 patients undergoing elective lower segment caesarean section under spinal subarachnoid block. This study was conducted over a period of 6 months after obtaining ethical review board approval and informed consent from each patient. A proforma was made prior to starting the study; 100 patients who consented to be administered diclofenac suppository as preemptive analgesia was included in the study. The second dose of rectal diclofenac was meant to be self-administered by the patient when she felt pain (McGill's pain score - 1). Preoperative counselling was given regarding the advantages of the rectal route of administration over other routes to all patients as well as the method of self-placement of rectal suppository. They were assured of the choice of other modes of analgesia for postoperative pain if they found selfadministration of rectal diclofenac inconvenient. Patients with history of coexistent illnesses like hypertension, diabetes mellitus, bronchial asthma, allergy to diclofenac or other NSAIDs, patients with lesions in or bleeding from anal canal were excluded from the study.

All patients were subjected to thorough preoperative assessment. They were kept nil orally for 6 hours prior to surgery. Baseline pulse rate, blood pressure and respiratory rate were recorded. A wide bore intravenous access was established. Premedication with Injection ranitidine $50 \mathrm{mg}$ and Injection metoclopramide was given 30 minutes before surgery. Lumbar subarachnoid block was administered in the standard method in the lateral decubitus position. Immediately after lumbar subarachnoid block was administered with the patient in the same position, polyethylene glycol based diclofenac suppository $100 \mathrm{mg}$ was moistened with a water soluble lubricant and inserted per rectally.

One hour after administration of spinal subarachnoid block was taken as 'zero hours.' Before shifting the patient at the time of vaginal toilet, it was visually confirmed that the rectal suppository had not come out. Postoperative analgesia was recorded using McGill pain score where the patient reported whenever she got slight pain (McGill score - 1). At the time patient complained of pain, she was asked about the requirement of further analgesia and if so the preferred route of administration which could be either oral, intramuscular or self-administered rectal. The number of patients who opted for repeat dose of self-administered rectal suppository was noted and the reason for denial of a repeat dose per rectum was recorded.

\section{RESULTS}

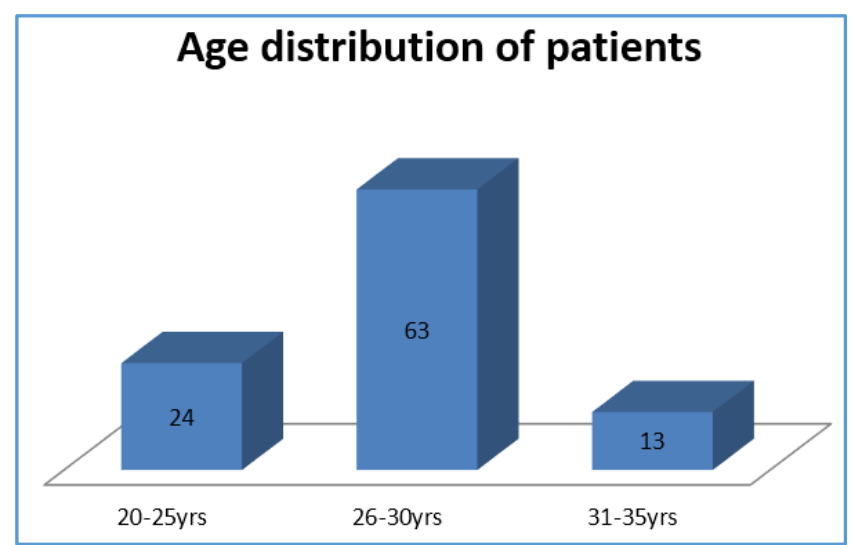

Figure 1. Age Distribution of Patients
Out of the 100 patients, 24 patients (24\%) belonged to 20 - 25 years' age group; 63 patients belonged to 26 - 30 years' age group and 13 patients belonged to 31 - 35 years. Of this 74 patients were undergoing repeat caesarean section, whereas 26 were undergoing primary caesarean section.

\section{Body mass index distribution}

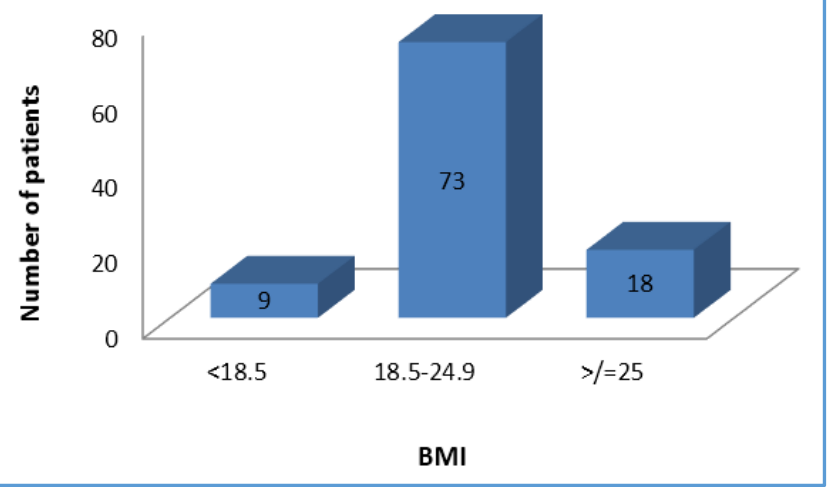

Figure 2. Body Mass Index Distribution of the Patients

9 patients out of the 100 were below normal BMI $(<18.5)$, while 18 patients were overweight/obese (BMI $\geq 25) ; 73$ women fell in the normal BMI range (18.5 - 24.9).

\section{Hours of Analgesia}

The mean hours of analgesia in the participants was 16.43 hours Standard Deviation \pm 4.82 hrs. The hours of analgesia experienced ranged from a minimum of 10 hours to a maximum of 24 hours, after which the second dose analgesic had to be administered.

\begin{tabular}{|c|c|c|c|}
\hline $\begin{array}{c}\text { Number of } \\
\text { Patients }\end{array}$ & Mean & $\begin{array}{c}\text { Standard } \\
\text { Deviation }\end{array}$ & $\begin{array}{c}\mathbf{9 5 \%} \\
\text { Confidence } \\
\text { Interval }\end{array}$ \\
\hline 100 & 16.43 & 4.82 & $16.43 \pm 4.82$ \\
\hline \multicolumn{3}{|c|}{ Table 1. Hours of Analgesia Obtained } \\
\hline
\end{tabular}

\section{Acceptance of Second Dose of Rectal Analgesia}

Out of the 100 patients 7 patients did not demand a second dose of analgesic, as they did not have significant pain.

The remaining 93 patients were given a choice of selfadministered rectal diclofenac suppository, oral diclofenac tablet if they had started oral feeds or intramuscular diclofenac preparation.

Of the remaining 93 patients 21 patients opted for the rectal route, 68 patients opted for oral route and 4 patients opted for intramuscular route.

\begin{tabular}{|c|c|c|c|}
\hline $\begin{array}{c}\text { Route of } \\
\text { Administration }\end{array}$ & Rectal & Oral & Intramuscular \\
\hline $\begin{array}{c}\text { Number of } \\
\text { patients who } \\
\text { opted for repeat } \\
\text { analgesia }\end{array}$ & 21 & 68 & 4 \\
\hline Table 2. Route of Preference of Second Dose of Analgesic \\
\hline
\end{tabular}




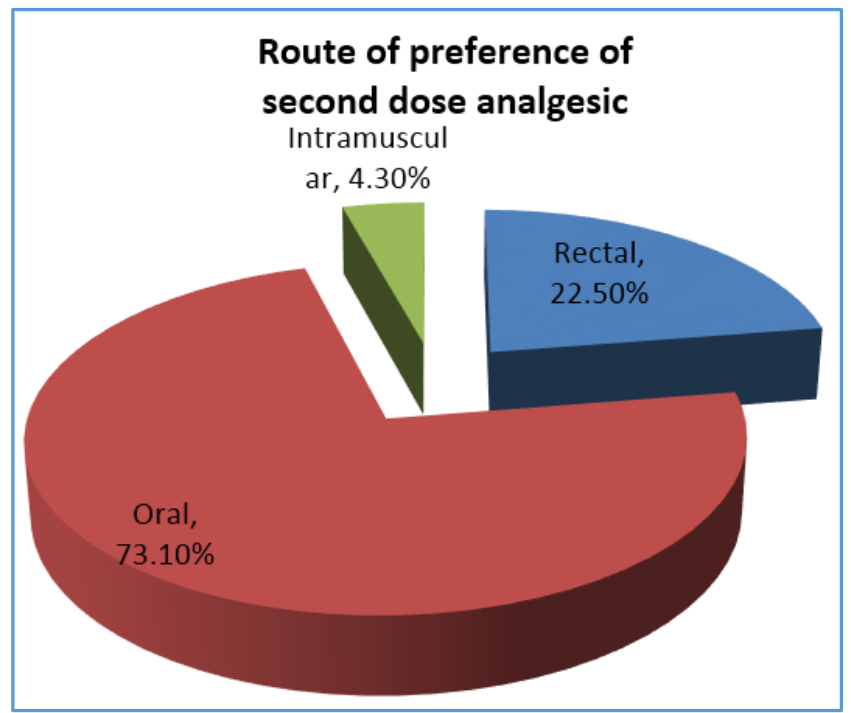

Figure 3

Out of the 93 patients who needed second dose analgesia, 21 of them (23\%) opted for self-administered rectal suppository; 68 patients opted for the oral route, as they had already started taking oral feeds.

Reasons Cited for not Preferring the Rectal Route as Second Dose

\begin{tabular}{|c|c|}
\hline Reasons Cited & Number of Patients \\
\hline Bleeding per vaginum & 14 \\
\hline $\begin{array}{c}\text { Lack of confidence in successful } \\
\text { placement }\end{array}$ & 37 \\
\hline Fear of infection & 5 \\
\hline Lack of privacy & 43 \\
\hline Oral feeds initiated & 28 \\
\hline Faith in intramuscular route & 4 \\
\hline \multicolumn{2}{|c|}{ Total } \\
Table 3. Reasons Cited for Not Preferring \\
the Rectal Route as Second Dose \\
\hline
\end{tabular}

Some patients (around 40\%) cited more than one reason for not preferring self-administered rectal dose as the second dose analgesia. The most common reason (46.2\%) cited was lack of privacy, as most of these patients were allotted beds in the general inpatient wards.

Number of Patients who would opt for per rectal Analgesia as their first Analgesic Dose in Subsequent Surgeries

92 patients were of the opinion that they would opt for per rectal analgesia as their first analgesic dose in subsequent surgeries.

\section{DISCUSSION}

The immediate postpartum period is very important for mother child bonding. ${ }^{8}$ This is the time for initiation into breast feeding, early initiation having definite advantages. ${ }^{9}$ So, it is very distressing if it is hampered by postoperative pain. Options for postoperative analgesia are opioids, NSAIDs, advantages of Diclofenac (Breast milk).

Pre-emptive analgesia is a method of antinociceptive treatment before the onset of painful stimuli with an aim to prevent sensitisation of the nervous system to subsequent stimuli that could amplify pain. ${ }^{10}$
In a surgical setting, the timing of noxious stimulus is known earlier and therefore it is the ideal setting to practice pre-emptive analgesia. Also, pre-emptive analgesia brings down the postoperative analgesic requirement. ${ }^{11,12}$

The rectal route of drug absorption is almost similar to the absorption from the upper part of the gastrointestinal tract. ${ }^{13}$ The venous drainage of the lower part of the rectum is unique, in that it bypasses the enterohepatic circulation, thus making more of the active drug available in circulation.

T-max of rectal diclofenac is reached in 1 hour, which is faster than the oral route. Advantage of polyethylene glycol based suppository is that it provides a rapid release of the drug, as its vehicle of transport is water soluble and water miscible. ${ }^{14}$

In our study, counselling was given to the expectant mothers before the Caesarean section regarding the advantages of the rectal route of diclofenac administration for postoperative pain relief. Patients who consented to take part in this study were convinced about the longer duration of analgesia obtained by this route, lesser side effects and lesser secretion of the drug through breast milk. The time of placement of the suppository could also have acted as a deciding factor, as no new procedure needed to be undertaken for its placement and the placement was done by the Anaesthesiologist. The method of self-administration in the postoperative period was also discussed with the patients. They were made aware that alternate modes of analgesia of their choice would be available to them, if they found rectal placement difficult.

21 patients $(23 \%)$ took rectal diclofenac as second dose of analgesic and were very satisfied with the results; 68 patients opted for oral route $(73 \%)$. The reasons cited by these patients were that they lacked privacy for placement of suppository, as they were admitted in the general inpatient ward; 37 patients cited that they lacked confidence in correct placement of suppository, as they had not done it before which was added on by the incompatible environment for placement; 28 patients had already started oral feeds, which included other oral medications and therefore opted for oral route; 14 patients refused to place rectal suppository as they had bleeding per vaginum, which they might have found messy. Fear of infection was also a deterrent factor cited by 5 patients; 4 patients opted for the invasive and painful intramuscular analgesic route, possibly because they had more faith in this mode of administration. Some patients cited more than 2 reasons for deferring the second dose rectal suppository. Hence, it was not possible to accurately calculate the relative contribution of each of the reasons.

92 patients $(92 \%)$ who participated in the study opined that they would prefer rectal diclofenac suppository, administered by health care professionals as pre-emptive analgesia for postoperative pain relief for any subsequent surgeries they may undergo. This may again possibly be due to the avoidance of the hassle of self-administration of rectal suppository.

Of the 72 patients, among the 93 who opted for other routes of second dose analgesia 63 patients (87.5\%) said that they would have opted for rectal diclofenac as second dose analgesic if it was administered by a health care professional. 
Since all the patients were placed in the general inpatient ward, lack of privacy was one of the major reasons for nonacceptance of rectal route for second dose analgesia. Thus, it is seen that hospital environment plays a decisive role in the acceptance of treatment modalities, which is a major contributor to satisfaction levels and wellbeing of the patient. 15

\section{CONCLUSION}

Pre-emptive rectal diclofenac suppository is an effective method of tackling post-operative pain. Its acceptance level when administered by a health care professional is high, whereas self-administration of rectal diclofenac suppository as a second dose analgesic is low. The common reasons of nonacceptance are lack of privacy and low confidence regarding the correct placement. Ensuring privacy, especially in the postoperative period for the postpartum patient will improve the acceptance of rectal diclofenac. Patient education and information leaflets may also improve acceptance of an alternate route of drug delivery.

\section{ACKNOWLEDGEMENT}

We thank all the patients who consented to take part in this study. We also thank our colleagues who helped us with the study.

\section{REFERENCES}

1. Ong CK, Lirk $\mathrm{P}$, Tan CH, et al. An evidence-based update on nonsteroidal anti-inflammatory drugs. Clinical medicine \& research 2007;5(1):19-34.

2. Malhotra K, Tyagi C, Gangwar N, et al. Evaluation of preoperative rectal diclofenac for perioperative analgesia in ENT surgery. Indian Journal of Anaesthesia 2003;47(6):463-6.

3. Lim NL, Lo WK, Chong JL, et al. Single dose diclofenac suppository reduces post-cesarean PCEA requirements. Canadian journal of anaesthesia 2001;48(4):383-6.

4. Ejnell H, Björkman R, Wåhlander L, et al. Treatment of postoperative pain with diclofenac in uvulopalatopharyngoplasty. British journal of anaesthesia 1992;68(1):76-80.
5. Marel CD, Anderson BJ, Rømsing J, et al. Diclofenac and metabolite pharmacokinetics in children. Pediatric Anesthesia 2004;14(6):443-51.

6. Dodd JM, Hedayati H, Pearce E, et al. Rectal analgesia for the relief of perineal pain after childbirth: a randomised controlled trial of diclofenac suppositories. BJOG: an international journal of obstetrics \& gynaecology 2004;111(10):1059-64.

7. Beckett $\mathrm{AH}$, Burgess $\mathrm{CD}$, Johnston $\mathrm{A}$, et al. The systemic availability of a slow release rectal preparation of lignocaine [proceedings]. British journal of clinical pharmacology 1978;6(5):442-3.

8. Rocha SM, Simpionato E, de Mello DF. Mother-child bonding: comparative study of mothers after normal delivery and cesarean section. Revista brasileira de enfermagem 2002;56(2):125-9.

9. Edmond KM, Kirkwood BR, Amenga-Etego S, et al. Effect of early infant feeding practices on infection-specific neonatal mortality: an investigation of the causal links with observational data from rural Ghana. American journal of clinical nutrition 2007;86(4):1126-31.

10. Gottschalk A, Smith DS. New concepts in acute pain therapy: preemptive analgesia. American family physician 2001;63(10):1979-84.

11. Rao M. Acute post-operative pain. Indian Journal of Anaesthesia 2006;50(5):340-4.

12. Woolf CJ, Chong MS. Preemptive analgesia-treating postoperative pain by preventing the establishment of central sensitization. Anesthesia Analgesia 1993;77(2): 362-79.

13. Bergogne-Bérézin E, Bryskier A. The suppository form of antibiotic administration: pharmacokinetics and clinical application. Journal of Antimicrobial Chemotherapy 1999;43(2):177-85.

14. Goyan JE, Milton W (inventors). Upjohn Co, assignee. Polyethylene glycol suppository bases. United States patent US 2,975,099. 1961 Mar 14.

15. Sadeghi N, Abdeyazdan Z, Motaghi M, et al. Satisfaction levels about hospital wards environment among adolescents hospitalized in adult wards vs pediatric ones. Iranian journal of nursing midwifery research 2012;17(6):430-3. 